\title{
EAD E EVOLUÇÃO TECNOLÓGICA: OS NOVOS PARADIGMAS DO MATERIAL DIDÁTICO
}

\section{DISTANCE EDUCATION AND TECHNOLOGICAL EVOLUTION: THE DIDACTIC MATERIAL NEW PARADIGMS}

\author{
Cid Boechat, Mestrando em Design. ${ }^{1}$ \\ Claudia Mont'Alvão, D.Sc. ${ }^{2}$ \\ (1) PPGDesign, Lab Ergodesign e Usabilidade de Interfaces LEUI PUC-Rio \\ e-mail: cidboechat@gmail.com \\ (2) PPGDesign, Lab Ergodesign e Usabilidade de Interfaces LEUI PUC-Rio \\ e-mail: cmontalvao@puc-rio.br
}

Educação a Distância, Metodologias Colaborativas do Design, Equipes Multidisciplinares

Reflete-se, aqui, sobre a relação entre a Educação à Distância (EAD) e as mídias que a compõe. O artigo discute como as novas tecnologias exigem uma diferente interação de alunos e professores com o material didático e também a formação de equipes técnicas multidisciplinares. Como proposta, sugere-se a utilização das metodologias do Design e da Macroergonomia como ferramentas organizacionais para as equipes que atuam nesses ambientes educacionais.

\section{Distance Education, Collaborative Design Methodologies, Multidisciplinary Teams}

This paper presents the relationship between Distance Education and its media. It is discussed how the new technologies require different kinds of interactions of teachers and students with the courseware and the formation of multidisciplinary technical teams. As a proposal, it suggests the use of Design methodologies and Macroergonomics as organizational tools for the teams in these educational environments.

\section{Introdução}

Segundo o Censo da Educação Superior de 2013, a Educação a Distância (EAD) cresceu 35,3\% no número de cursos oferecidos entre 2010 e 2013. Nesse mesmo período, registrou aumento de $24 \%$ nas matrículas e de $35,5 \%$ no ingresso de alunos. Se olharmos para os números desde a década passada, perceberemos que entre 2003 e 2013 a
EAD superior registrou impressionantes $2.200 \%$ de aumento (BRASIL, 2015), passando de menos de 50.000 matrículas para mais de 1,1 milhão. A possibilidade de vencer distâncias e aumentar o número de vagas oferecidas fora dos grandes centros e capitais dão à EAD um papel importante. Porém, ela precisa se relacionar com a qualidade e as especificidades que a modalidade demanda.

A Educação a Distância pode apresentar, graças as
Realização:

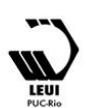




\section{$16^{\circ}$ \\ ERGODESIGN USIHC CINAHPA}

suas características intrínsecas e questões culturais, dificuldades de adoção e implementação por parte de alunos e profissionais. Segundo Moran, Valente e Arantes (2011), muitos se sentem desconfortáveis nos ambientes virtuais, demoram a se adaptar e sentem falta da turma presencial. $\mathrm{O}$ ambiente digital, para quem não está acostumado, pode ser confuso e distante.

\begin{abstract}
A EaD consiste em uma modalidade de educação em que não só professores e alunos estão separados fisicamente, mas a proposta de ensino é diferenciada (MAIA; MATTAR, 2007). Segundo Ives e Javenpaa (1996), o papel do professor nessa modalidade constituise muito mais como facilitador do que de especialista, pois os cursos costumam ser menos estruturados e mais personalizados, cabendo aos próprios alunos atentar para a sua instrução (OLIVEIRA, 2013, p. 4).
\end{abstract}

Não fossem estas questões complicadoras por si só, temos a velocidade do surgimento de novas tecnologias e a necessidade de adoção das mesmas pelas instituições. Esse fato tornou o ensino superior a distância um desafio ainda maior e mais complexo. Convém notar que a explosão da EAD no Brasil ocorreu num período de dez anos onde avanços como smartphones, e-books e tablets causaram mudanças de paradigmas sociais e educacionais (Tabela 1 ).

\begin{tabular}{|l|l|}
\hline \multicolumn{1}{|c|}{ Mudança Tecnológica } & \multicolumn{1}{c|}{ Ano de surgimento } \\
\hline Moodle 1.0 & 2002 \\
\hline Skype & 2003 \\
\hline Orkut e Facebook & 2004 \\
\hline YouTube & 2005 \\
\hline Iphone e Kindle e-reader & 2007 \\
\hline Android OS e 3G (no Brasil) & 2008 \\
\hline Ipad & 2010 \\
\hline 4G (no Brasil) & 2012 \\
\hline
\end{tabular}

Tabela 1- Algumas mudanças tecnológicas surgidas no período de forte crescimento da EAD brasileira. (Fonte: o autor, com base na pesquisa realizada) $16^{\circ}$ Ergodesign - Congresso Internacional de Ergonomia e Usabilidade de Interfaces Humano Tecnológica: Produto, Informações Ambientes Construídos e Transporte

$16^{\circ}$ USIHC - Congresso Internacional de Ergonomia e Usabilidade de Interfaces Humano Computador

CINAHPA | 2017 - Congresso Internacional de Ambientes Hipermídia para Aprendizagem.

As novas TICs (Tecnologias de Informação e Comunicação) aumentaram, além dos custos, a necessidade de formação de equipes multidisciplinares para a construção de material didático.
A adaptação do conteúdo didático às novas mídias é muito caro e requer linguagem e recursos visuais específicos, além de pessoas especializadas que trabalhem em parceria com os professores (OLIVEIRA, 2013, p. 5).

Neste processo, pode-se precisar de profissionais como conteudistas de várias áreas, designers instrucionais, designers gráficos, ilustradores, web designers, programadores, tutores, revisores, entre outros.

Pode-se dizer, então, que esses fatores mudaram a interação de alunos e professores com o material didático. O paradigma educacional se modificou. Mudou, também, a própria abordagem das Instituições de Ensino Superior (IES), que necessitam de uma equipe maior de produção do material. Elas devem ser velozes para acompanhar as tendências e ferramentas educacionais que os alunos demandam. Não surpreenderia se todos esses fatores trouxeram consigo novas necessidades de gestão e organização desse trabalho. Segundo os Censos EAD.br de 2013 e de 2014 da Associação Brasileira de Educação a Distância (ABED), os desafios organizacionais representam o segundo maior obstáculo encontrado pelas instituições que passam a oferecer EAD, atrás apenas da evasão de alunos.

Considerando o cenário delineado até aqui, o presente artigo propõe uma reflexão baseada nas dificuldades da Educação a Distância e no novo tipo de interação que professores, alunos e técnicos precisam construir entre si. O texto abordará a nova relação que essas pessoas precisam ter com o material didático. Se todas essas mudanças trouxeram problemas, como podemos buscar soluções através das metodologias do Design e da Ergonomia que se aplicam sobre sistemas de trabalho?

Primeiramente, $o$ artigo contextualiza a EAD no Brasil até o cenário atual, abordando dados
Realização:

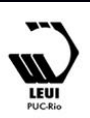




\section{$16^{\circ}$ \\ ERGODESIGN USIHC CINAHPA}

$16^{\circ}$ Ergodesign - Congresso Internacional de Ergonomia e Usabilidade de Interfaces Humano Tecnológica: Produto, Informações Ambientes Construídos e Transporte

$16^{\circ}$ USIHC - Congresso Internacional de Ergonomia e Usabilidade de Interfaces Humano Computador

CINAHPA | 2017 - Congresso Internacional de Ambientes Hipermídia para Aprendizagem. levantados, características gerais, obrigações legais e problemas encontrados. $\mathrm{O}$ foco da análise são os cursos de graduação, mais dependentes das equipes multidisciplinares. Além disso, os cursos superiores possuem obrigações semipresenciais, mais processos internos e maior exigência da legislação. Em seguida, o texto abordará: a relação intrínseca entre EAD e as diferentes mídias; as mudanças nos paradigmas da educação e da EAD trazidas pelas novas TICs; e as mudanças na construção do material e na interação dos atores envolvidos no processo. Quais os desafios enfrentados por esses profissionais e quais problemas organizacionais podem advir disso. Como reflexão final, o artigo propõe o uso de metodologias participativas do Design e da Macroergonomia como ferramentas de apoio e gestão do trabalho nesse novo cenário.

\section{EAD: desenvolvimento e contexto atual}

As origens da EAD remontam à cursos por correspondência que visavam ampliar, para a população mais pobre, a oferta de educação básica e preparação para o trabalho. Segundo Mugnol (2009), a Educação a Distância era então vista preconceituosamente como inferior e de nível baixo, estigmas que persistiriam até hoje. Ao longo do século XX, a EAD foi se consolidando graças a avanços tecnológicos como o telefone e o rádio. No Brasil, por exemplo, um dos marcos do ensino a distância se deu na década de 1920, através da Rádio Sociedade do Rio de Janeiro (SARAIVA, 1996). Comandada na época por Roquette-Pinto, a rádio utilizou um plano sistemático educacional de radiodifusão como forma de ampliar o acesso à educação (OLIVEIRA, 2013, p.3).

Segundo Mugnol (2009), a EAD recebeu maior impulso ao ser encampada pelo poder público no início dos anos 1990. Isso ocorreu através de programas a distância de formação continuada de professores nas redes municipais e estaduais. Em 1996, com a publicação de Lei de Diretrizes e Bases da Educação Brasileira (LDB), a Educação a Distância se torna efetivamente uma política pública. Arruda e Arruda (2015, p.323) afirmam que se, historicamente, a EAD brasileira começa no século XIX, seu marco regulatório só acontece com a promulgação da LDB. A lei versa que é obrigação do Estado incentivar o desenvolvimento e veiculação de programas de EAD em todos os níveis e modalidades de ensino e de educação continuada. Além disso, cabe ao Estado também regular, controlar e credenciar instituições provedoras de Educação a Distância (BRASIL, 1996). Andrade e Lopes (2012, p.10) sublinham que a LDB direcionou um novo olhar para a EAD, que passou a contar com os requisitos para a realização de exames pela União e registros de diplomas relativos a cursos de Educação a Distância.

Além da redação original da LDB, a EAD também teve destaque no PNE (Plano Nacional da Educação) aprovado através da Lei $n^{\circ} 10.172$, de 2001. O PNE tem duração de dez anos e deve servir de parâmetro para Estados, Municípios e Sociedade Civil construírem seus planos decenais. No PNE 2001-2010, o Governo Federal deixava claro que considerava a EAD uma solução eficaz para os baixos índices de acesso aos cursos superiores e para o processo de universalização e a democratização do ensino (BRASIL, 2001).

No que tange a graduação, a legislação brasileira permite o oferecimento a distância de formações profissionais tecnológicas, programas e cursos de educação superior sequenciais e de graduação. Há também a oferta de especialização, mestrado e doutorado. Na prática, a lei exige que os cursos superiores, mesmo os ditos $100 \%$ a distância, sejam semipresenciais. Isso ocorre pois é compulsória a presença do aluno em provas de avaliação, estágios obrigatórios, defesas de trabalhos de conclusão de curso e atividades relacionadas a laboratórios (BRASIL, 1996). Essas exigências aumentam as necessidades de estrutura, pessoal e gestão, para que as disciplinas funcionem corretamente nos parâmetros governamentais determinados pela lei.

Os cursos de graduação, mais extensos, exigem estrutura e processos de funcionamento mais complexos. Estariam, por esse motivo, mais sujeitos ao estranhamento de atores fundamentais, erros processuais e estruturais e aos gargalos de produção. Seu funcionamento depende de uma
Realização:

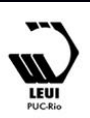




\section{$16^{\circ}$ \\ ERGODESIGN USIHC CINAHPA}

cadeia maior de eventos e de pessoas interagindo.

Não fossem estas questões importantes o suficiente, somaram-se à aposta governamental na EAD fatores como programas de financiamento estudantil e questões econômicas. Elas permitiram à graduação a distância um crescimento exponencial de $2.200 \%$ entre 2003 e 2013.

Exatamente num período onde mudanças tecnológicas e novas TICs como smartphones, tablets, e-books, e-readers, redes sociais, videochat e sistemas de gestão de ensino quebraram paradigmas. Com isso, foram atingidos dois pontos fundamentais da EAD: a forma como alunos e professores interagem e a produção de materiais didáticos.

\section{As novas tecnologias e o material didático}

A Educação a Distância se caracteriza, desde os seus primórdios, pelo uso de tecnologias de informação e comunicação para vencer o hiato entre professor e aluno. Partindo de aulas por correspondência, livros didáticos, radiodifusão, teleducação, até recentes tecnologias como streaming de vídeo, Realidade Aumentada, TV Digital interativa e Ambientes Virtuais de Aprendizagem. Segundo Behar (2009, p.16), a EAD pode ser definida como uma aprendizagem organizada, em que há separação física entre professores e alunos e a interação entre eles se realiza através de alguma tecnologia de midiação.

Ao se abordar o estado atual da EAD, não se pode ignorar o papel das novas TICs e das inovações tecnológicas. Elas atuam instrumentalmente na relação professor-aluno e no paradigma educacional e cultural. Segundo Formiga (2009, p.39), a EAD está intrinsecamente ligada às TICs pelo seu dinamismo e a capacidade de inovação. Segundo o autor, a sociedade da informação "reflete-se na EAD pela apropriação célere dos conceitos e inovações, que moldam a mídia e se refletem na própria EAD”.

A popularização dos computadores, aparelhos móveis e da internet modificaram a "ponte" entre alunos e professores. Teixeira e Weschenfelder (2013) afirmam que se pode falar de uma EAD $16^{\circ}$ Ergodesign - Congresso Internacional de Ergonomia e Usabilidade de Interfaces Humano Tecnológica: Produto, Informações Ambientes Construídos e Transporte

$16^{\circ}$ USIHC - Congresso Internacional de Ergonomia e Usabilidade de Interfaces Humano Computador

CINAHPA | 2017 - Congresso Internacional de Ambientes Hipermídia para Aprendizagem.

antes e outra depois da internet e das tecnologias ligadas a ela:

Antes da internet tinha-se uma EAD que utilizava apenas tecnologias de comunicação de "um-para-muitos" (rádio, TV) ou de "um-paraum" (ensino por correspondência). Via internet há as três possibilidades de comunicação reunidas numa só mídia: "um-para-muitos", "um-para-um" e, sobretudo, "muitos-paramuitos" (TEIXEIRA; WESCHENFELDER, 2013, p.7 e 8).

Moran (2012) nos lembra que estamos saindo de uma EAD massiva, de produto pronto, para modelos flexíveis, que combinam o individual com momentos coletivos e colaborativos. As tecnologias WEB 2.0 facilitam a aprendizagem entre colegas e torna o processo mais aberto, ágil e intuitivo.

Como medir no nosso cotidiano, por exemplo, as mudanças que as redes sociais trouxeram? No âmbito da EAD, Litto $(2009$, p. 17) reafirma que as redes sociais têm grande importância, pois dão mais possibilidades para a colaboração e o compartilhamento entre alunos e docentes. Ainda segundo o autor, a Web 2.0 traz mais interatividade e oferece hospedagem online de conteúdos e programas. Além disso, fornece ferramentas de aprendizagem, como agendas, organizadores pessoais, ambientes colaborativos e recursos audiovisuais.

Como pode-se observar na Tabela 2 , redes sociais como o Facebook e o Google + também são citadas como ferramentas de compartilhamento de material com os alunos, apesar desta não ser a sua atividade-fim.

A lista disponibilizada na Tabela 2 é um bom parâmetro do atual estágio do material didático na EAD. Por ela, percebe-se que a maioria das IES usa maciçamente os AVAs (Ambientes Virtuais de Aprendizagem) para disponibilização de conteúdo e comunicação com os alunos (ABED, 2015). O Moodle, por exemplo, é um LMS (Learning Management System) gratuito, livre e aberto, que permite a criação de um AVA com várias funcionalidades para o semipresencial e a
Realização:

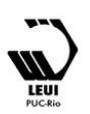




\section{$16^{\circ}$ \\ ERGODESIGN USIHC CINAHPA}

distância. Segundo Andrade e Lopes (2012) educar em AVAs requer maior dedicação do professor e apoio da equipe técnica-pedagógica. $\mathrm{O}$ curso precisa de mais tempo de elaboração e de um acompanhamento mais sólido de todo o processo. Analisando as afirmações de Silva (2003), os autores justificam o uso do AVA pelo ganho dos alunos com a personalização da aprendizagem, adaptando-a ao seu ritmo de vida. A grade curricular e os tipos de atividades se tornam mais flexíveis.

\begin{tabular}{|l|c|}
\hline \multicolumn{1}{|c|}{ Opções } & Respostas \\
\hline $\begin{array}{l}\text { Ambiente Virtual de Aprendizagem gratuito } \\
\text { (Moodle, Teleduc, Sakai, etc.), locado } \\
\text { (Blackboard, Webaula, Aulanet, etc.) ou próprio } \\
\text { (desenvolvido pela instituição) }\end{array}$ & 244 \\
\hline E-mail ou listas/grupos de e-mail & 78 \\
\hline $\begin{array}{l}\text { Grupos em redes sociais (Facebook, Google+, } \\
\text { etc.) }\end{array}$ & 49 \\
\hline Grupos de chat (WhatsApp, Telegram, etc.) & 27 \\
\hline Blogs & 22 \\
\hline $\begin{array}{l}\text { Canais da Wikimedia Foundation } \\
\text { (Wikiversidade, Wikipédia Commons, etc.) }\end{array}$ & 3 \\
\hline Google Drive & 31 \\
\hline Dropbox & 16 \\
\hline Scribd & 10 \\
\hline Flickr & 28 \\
\hline YouTube & 10 \\
\hline Vimeo & \\
\hline Outro(s) & \\
\hline Tabela 2- Ferament & \\
\hline
\end{tabular}

Tabela 2 - Ferramentas utilizadas pelas IES para o compartilhamento de materiais com os alunos (Fonte: Censo ABED 2014)

A velocidade do desenvolvimento tecnológico e da sua adoção por parte dos alunos explica a visão de Litto (2009, p.18), quando afirma que, no passado, os dirigentes das instituições de ensino determinavam as tecnologias com as quais os alunos aprenderiam. Nos dias atuais, os dirigentes $16^{\circ}$ Ergodesign - Congresso Internacional de Ergonomia e Usabilidade de Interfaces Humano Tecnológica: Produto, Informações Ambientes Construídos e Transporte

$16^{\circ}$ USIHC - Congresso Internacional de Ergonomia e Usabilidade de Interfaces Humano Computador

CINAHPA | 2017 - Congresso Internacional de Ambientes Hipermídia para Aprendizagem. teriam que buscar adaptação às tecnologias que os alunos já possuem.

Isso pode ficar mais explícito se olharmos o caso do uso educacional dos dispositivos móveis. De acordo com matéria publicada no site do jornal $\mathrm{O}$ Globo em 18 de junho de 2016, 38,3 milhões de brasileiros acessam a internet através de celulares ou tablets. Desse grupo, 8,7 milhões utilizam apenas dispositivos móveis para se conectar. Além disso, segundo matéria publicada em 06 de janeiro de 2015 no site do jornal Diário do Nordeste, os brasileiros são líderes no uso de smartphones na América Latina e ocupam o sexto lugar no ranking mundial. Ainda assim, o Censo da ABED (2015, p.9) aponta que, de 254 instituições pesquisadas, $174(68,5 \%)$ ainda não haviam incorporado dispositivos móveis nos cursos de EAD que ofereceram em 2014.

Esse cenário exemplifica a necessidade contínua de investimento das IES em inovação. Segundo a $\operatorname{ABED}(2015$, p.8), a maioria das instituições consultadas declara que investe em tecnologia, inovação e na produção de novos cursos ou módulos. Outra necessidade que advém desse cenário é formação de equipes técnicas multidisciplinares para a construção desse material. Ainda segundo a ABED (2015, p. 9), a maioria das IES produz seu próprio material textual e audiovisual. Essa informação reforça a importância da formação e do bom funcionamento de equipes para produção do material didático.

Em 2014, 11\% dos cursos a distância regulamentados ofereceram conteúdo exclusivamente físico aos alunos, enquanto $63 \%$ já ofereciam apenas materiais digitais online e $23 \%$ combinavam digitais com físicos (ABED, 2015). Isso demonstra que as IES têm necessidade de produção e adaptação pedagógica de diferentes mídias. Nesse contexto, um curso de graduação pode precisar de professores conteudistas, desenhistas instrucionais, especialistas em filmagem e edição de vídeo e/ou áudio e profissionais de programação e/ou web design apenas para a construção de seu material didático. Moreira (2009, p.372) lembra que, num projeto EAD de pequena escala, profissionais ainda 


\section{$16^{\circ}$ \\ ERGODESIGN USIHC CINAHPA}

conseguem acumular funções (autor, designer instrucional, tutor, etc.). Por outro lado, projetos mais amplos, envolvendo a produção e gestão de diferentes mídias, demandam a composição de uma equipe mais numerosa e com papéis diferenciados.

Mas essas são apenas questões e demandas técnicas da relação entre TICs e EAD. Há outra, tão importante quanto. É preciso lembrar que esse cenário traz questões pedagógicas inerentes que influem na produção do material didático e na abordagem dos professores em relação aos alunos.

\section{EAD, TICs e os desafios pedagógicos}

As TICs são ferramentas com imensas possibilidades, mas que dependem e demandam uma abordagem pedagógica diferenciada, especialmente na EAD. Búrigo et al. (2016, p.169) reforçam que as ações pedagógicas ocupam lugar central no processo de gestão da educação a distância porque atendem as necessidades de ensino e de aprendizagem. O processo pedagógico, assim, motiva a definição dos meios, da produção dos materiais e do sistema de comunicação, integrando as equipes no objetivo de fomentar o processo de aprendizagem dos alunos.

Coutinho (2009, p.312), nesse aspecto, lembra que a maior dificuldade dos docentes não está na utilização das ferramentas em si, mas na elaboração pedagógica. Ela demanda mais tempo de preparo e traz dificuldades na criação das estratégias diversificadas que a EAD exige. Para Moran (2013), as tecnologias trazem muitas possibilidades, mas sem um trabalho paralelo sólido e constante de formação, passa a ser subutilizada pelos professores após a empolgação inicial.

Um curso a distância, por sua complexidade, não pode abrir mão de ser dialógico. $\mathrm{E}$ as formas de diálogo são amplas e variadas com as novas TICs. Palange (2009, p.379 e 380), citando as definições de Porto (2006), lembra que a educação é um processo comunicacional em que alunos e professores estabelecem uma relação educativa dialógica e plural. Ao preparar um curso, o $16^{\circ}$ Ergodesign - Congresso Internacional de Ergonomia e Usabilidade de Interfaces Humano Tecnológica: Produto, Informações Ambientes Construídos e Transporte

$16^{\circ}$ USIHC - Congresso Internacional de Ergonomia e Usabilidade de Interfaces Humano Computador

CINAHPA | 2017 - Congresso Internacional de Ambientes Hipermídia para Aprendizagem. educador organiza o desenho pedagógico a partir de sua visão de educação e comunicação. Assim, é necessário construir a possibilidade de que o outro fale, se expresse, tenha voz. Segundo Mattar (2009, p.112), a interatividade, complexa por si só, é ainda mais complicada em termos de EAD. Isso ocorreria, pois "diversos agentes interagem de diferentes maneiras, utilizando inúmeras ferramentas e com expectativas e objetivos bastante distintos". O desenvolvimento constante da tecnologia traz cotidianamente novas formas de interação. Isso obriga os profissionais e estudiosos da área a revisitar o conceito com frequência.

Para Mugnol (2009, p.338), a natural distância física entre alunos e professores da EAD, somada à comunicação através do uso de mídias, são um desafio para as IES. Exigem investimentos não só em tecnologia para mediação, como também representam uma mudança na cultura de professores e alunos que têm como parâmetro a educação presencial.

O desenvolvimento tecnológico, se é um fato praticamente inescapável, não pode prejudicar a interação professor-aluno. Saraiva (1996, p.17) lembra que a EAD só se realiza quando há uma verdadeira comunicação bilateral nitidamente educativa. Ela precisa ultrapassar a simples disponibilização de material instrucional. A EAD exige atendimento pedagógico que promova a relação professor-aluno através de estratégias institucionais.

Para Formiga (2009, p.43), o papel das TICs e a valorização da inovação criam um novo paradigma de aprendizagem flexível. Para os professores, caberá não mais a simples transmissão de conhecimento, mas deslocar sua competência para $o$ incentivo à aprendizagem, para raciocinar, pensar, falar e escrever melhor.

Mas a necessidade de se mudar a forma de abordar o material e a interação com os alunos não atinge só os docentes. O uso de cada vez mais recursos acaba exigindo mais dos desenhistas instrucionais, tutores e conteudistas. Para Nunes (2009, p.17), a tecnologia torna o ensino mais complexo. Assim, o papel do docente na EAD superior se transforma. 


\section{$16^{\circ}$ \\ ERGODESIGN USIHC CINAHPA}

Isso ocorre, pois os autores criam conteúdos que serão entregues em diferentes mídias (livros, vídeo e podcasts, entre outros). Material que precisará ser pensado e adaptado. Já a tutoria, passa a ser a distância, individualizada e "mediatizada através de diversos meios acessíveis".

Outros personagens fundamentais nesse cenário são as equipes técnicas multidisciplinares que constroem esse material. Segundo Moore e Kearsley (2007), as técnicas especiais de criação de curso e de instrução da EAD exigem arranjos organizacionais e administrativos especiais. Porém, Moran (2011) afirma que muitas IES banalizam a EAD; pensam que é fácil, barata e que pode ser funcional com recursos mínimos e pouca especialização dos funcionários.

Mas os profissionais responsáveis pela construção do material didático não precisam apenas de conhecimento técnico específico e estrutura de trabalho. Também são necessários um perfil pessoal e arranjos organizacionais que favoreçam o diálogo e a troca de experiências entre técnicos e docentes. Para Moreira (2009, p. 370 e 371), a conexão, na EAD, não é só dos computadores formando redes, mas entre pessoas. Isso demanda estratégias pedagógicas diferenciadas e um processo eficaz de gestão de processos e de pessoas que considere as novas formas de aprender em uma sociedade conectada.

Formiga (2009) afirma que o trabalho na produção e construção de conteúdo EAD requer um perfil de inovação próprio:

Trabalhar com a EAD requer profissionais e atores sensíveis e dispostos à inovação, porque atuam em um setor de transitoriedade, no qual a única certeza é a permanente mudança (...) não há espaço para conservadores ou acomodados, exigem-se atividades ousadas e celeridade nas decisões, que obrigatoriamente envolvem riscos nas opções com as quais se defronta. Estar sempre de cabeça aberta às novidades e ser flexível para mudar a qualquer momento. Não é um território para dogmas ou verdades absolutas (FORMIGA, 2009, p.39).

A composição e funcionamento da equipe deve levar em conta o perfil dos alunos e professores, as características do processo de ensinoaprendizagem e as mídias utilizadas. Além disso, devem ser consideradas as instituições, as políticas, a comunidade e a formação dos integrantes envolvidos (MOREIRA, 2009, p.377). Tão importante quanto a montagem dessa equipe é a sua gestão pelas IES. É preciso atenção não só para que ela consiga realizar bem suas tarefas. É fundamental que os atores de diferentes perfis dialoguem interna e externamente e compreendam o processo educacional e didático como um todo, para além do seu trabalho.

\section{A gestão da multidisciplinaridade na EAD}

Como afirmam Mallmann e Catapan (2007, p. 64), a multidisciplinaridade permeia toda a concepção e desenvolvimento da $\mathrm{EAD}$, pois a relação entre os atores é multidimensional. Utilizando os conceitos de formação grupos de trabalho na EAD de Moreira (2009, p.373 e 374), pode-se dizer que, com pequenas diferenças entre o tamanho e tipo de instituição, as sub-equipes que formam o time multidisciplinar são: de autores ou conteudistas; pedagógica; desenho (design) instrucional; e arte. A Tabela 3 resume o perfil de cada uma delas:

\begin{tabular}{|c|l|}
\hline Sub-equipe & \multicolumn{1}{|c|}{ Perfil } \\
\hline $\begin{array}{c}\text { Autores ou } \\
\text { conteudistas }\end{array}$ & $\begin{array}{l}\text { Desenvolvem os conteúdos, selecionando e } \\
\text { reunindo os materiais, organizando e } \\
\text { propondo dinâmicas, estratégias e recursos } \\
\text { pedagógicos. }\end{array}$ \\
\hline Pedagógica & $\begin{array}{l}\text { Pode coordenar os subsistemas de concepção, } \\
\text { produção e avaliação dos cursos; desenvolver } \\
\text { pesquisas; promover discussões pedagógicas. }\end{array}$ \\
\hline $\begin{array}{c}\text { Desenho } \\
\text { (Design) }\end{array}$ & $\begin{array}{l}\text { Profissionais interdisciplinares, em especial } \\
\text { nas áreas de educação, comunicação e } \\
\text { tecnologia. Em geral, fazem: levantamento e } \\
\text { análise de necessidades de instrução; } \\
\text { levantamento do perfil dos alunos ou } \\
\text { usuários; concepção e planejamento do } \\
\text { projeto; conversão ou adaptação dos } \\
\text { conteúdos, adequando-os à mídia a ser } \\
\text { utilizada. }\end{array}$ \\
\hline Arte & $\begin{array}{l}\text { Responsável pela direção de arte, desenho } \\
\text { gráfico, animações, ilustrações, bem como } \\
\text { outras características como a navegabilidade, } \\
\text { usabilidade e conformidade com os padrões } \\
\text { internacionais. }\end{array}$ \\
\hline
\end{tabular}

Tabela 3 - Características das sub-equipes envolvidas na produção de material didático em EAD (Fonte: Baseado em MOREIRA, 2009, p.373 e 374)
Realização:

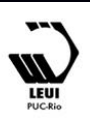




\section{$16^{\circ}$ \\ ERGODESIGN USIHC CINAHPA}

$16^{\circ}$ Ergodesign - Congresso Internacional de Ergonomia e Usabilidade de Interfaces Humano Tecnológica: Produto, Informações Ambientes Construídos e Transporte

$16^{\circ}$ USIHC - Congresso Internacional de Ergonomia e Usabilidade de Interfaces Humano Computador

CINAHPA | 2017 - Congresso Internacional de Ambientes Hipermídia para Aprendizagem.
Qual seria a melhor forma de gerir essa equipe que se divide em várias, mas precisa ser uma só? Qual o perfil de gerência que trará mais resultados consistentes com as características necessárias para o processo de aprendizagem esperado? A gestão correta do processo de produção do material é crucial para a EAD:
Em EaD o conceito de Gestão assume força central e singular no processo de elaboração dos materiais que contemplam todas as possibilidades didático-pedagógicas do curso. Pois, na concepção de uma proposta de curso na modalidade à distância a preparação do material é uma etapa de extrema importância. (...) A previsão das alternativas de interação é imprescindível para cada momento de aprendizagem que se fará autônomo, individual ou em grupos de estudantes (MALLMANN; CATAPAN, 2007, p.65).

Moreira (2009, p.371), concorda que os processos de produção se alteraram com as mudanças tecnológicas, políticas, econômicas, científicas e culturais. Citando Beloni (1999), a autora afirma que o sistema fordista não serve mais como parâmetro de funcionamento para a construção do material da EAD. A inovação demanda uma gestão de processos e pessoas mais integrada, como uma rede, que reflita "as novas formas de aprender em uma sociedade conectada". Nesse contexto, Búrigo et al. (2016, p.167 e 168) também apontam que modelos próximos ao Fordismo não podem mais ser utilizados no campo multidisciplinar da EAD. A produção massificada, com divisão de tarefas e unidades isoladas, permite pouca comunicação entre as equipes, especialmente entre aqueles que produzem e aqueles que administram. Citando Almeida (2004), os autores sublinham que é preciso uma ação colaborativa corresponsável na construção de planos, propostas e material.

Os ganhos da multidisciplinaridade dependem da forma como a organização constrói e gerencia a equipe. Excelentes profissionais podem produzir resultados abaixo de seu potencial, se trabalharem num ambiente ou modelo inadequados. Considerados esses conceitos, pode-se concordar com Mallmann e Catapan (2007, p.65) quando afirmam que a organização deve escolher metodologias de gestão que construam um campo de atuação flexível. Esse campo deve estar de acordo com as competências profissionais dos envolvidos. Pois, como lembra Moreira (2009, p. 374), o conceito pedagógico e o modelo de gestão partem das organizações. E eles influem na definição dos papéis e na distribuição e funcionamento de equipes.

Para que se atinja esse objetivo, é necessário conhecer o perfil pessoal e profissional de cada elemento. É preciso entendê-los, e construir um cenário onde possam render e dialogar, trazendo ganhos para todo o time. Mallman e Catapan (2007, p.66) corroboram essa importância, ao dizerem que "numa equipe multidisciplinar, em $\mathrm{EaD}$, atributos como o diálogo e a participação ativa de todos os envolvidos são essenciais".

Em resumo, as IES provedoras de Educação a Distância estão pressionada por mudanças tecnológicas profundas, demandas governamentais e questões multidisciplinares. Necessitam de arranjos organizacionais que permitam a interação entre seus atores e adequação técnica e pedagógica de seus processos.

Serão necessárias ferramentas para produzir um material adequado as especificidades da EAD. Ferramentas que levem em conta os perfis profissionais, o cenário externo e as características da organização. Ferramentas que, na busca por melhorias dos processos de trabalho, incluam as pessoas envolvidas na equipe multidisciplinar e abordem suas dificuldades cotidianas.

Será que essas respostas, essas ferramentas, não podem vir através de metodologias colaborativas do Design e da Ergonomia Organizacional, como a Macroergonomia?

\section{O uso do Ergodesign na gestão de EAD}

Para gerir equipes e sistemas de trabalho, o que o Design pode oferecer que outras abordagens não alcançaram? Segundo Buchanan (2015, p.5), a diferença vem de um princípio intrínseco do Design: o foco na qualidade da experiência de todos os servidos por uma organização. A 


\section{$16^{\circ}$ \\ ERGODESIGN USIHC CINAHPA}

preocupação não deve ser apenas com a lucratividade, mas, também, com a melhora significativa da vida das pessoas. Um princípio que traz consigo uma grande dificuldade: Como o Design pode influenciar as organizações para que busquem não somente a mudança do pensamento e do comportamento dos indivíduos, mas também um efeito positivo na vida das pessoas, num mundo cada vez mais complexo?

Com essa visão em mente, os designers perceberam que as organizações, em si, também poderiam ser tratadas como um projeto, se beneficiando de metodologias e de um "pensamento de design". Isso faria com que elementos pouco notados pelas análises tradicionais de gestão se sobressaíssem, gerando resultados diferenciados. Silva (2012, p.17) nos lembra que quando problemas de uma área são vistos pela ótica de outra, há um reposicionamento conceitual que levanta diferentes e novas questões. Assim, é possível chegar a soluções inovadoras.

A necessidade de criação de gestão organizacional em equipes multidisciplinares de EAD pode ser relacionada com a visão de design thinking de Brown (2009). Segundo ele, o Design deixa de ser apenas operacional para se tornar estratégico, conseguindo prover formas de integrar equipes, transformando o que é multidisciplinaridade em interdisciplinaridade. Esse novo Design, que se debruça sobre o funcionamento dos sistemas, é o passo seguinte ao foco sobre a interação e sua relação com ações, atividades e serviços. Ele busca a ideia organizadora ou princípio que opera por trás dos sistemas, organizações e ambientes - por trás de interações coletivas (BUCHANAN, 2015).

Da mesma forma, a Macroergonomia tem sua aplicabilidade no projeto dos sistemas de trabalho e foca na relação entre a Ergonomia e o Design Organizacional e a Gestão (HENDRICK, 2005, p.75-1). Segundo Hendrick e Kleiner (2002, p.3), a Macroergonomia atua na interface entre Homem e Organização (no inglês, HOI - Human-

Organization Interface) e nos fatores humanos, tecnológicos e contextuais (internos e externos à organização) que influem na hora de projetar e analisar sistemas de trabalho. $16^{\circ}$ Ergodesign - Congresso Internacional de Ergonomia e Usabilidade de Interfaces Humano Tecnológica: Produto, Informações Ambientes Construídos e Transporte

$16^{\circ}$ USIHC - Congresso Internacional de Ergonomia e Usabilidade de Interfaces Humano Computador

CINAHPA | 2017 - Congresso Internacional de Ambientes Hipermídia para Aprendizagem.
A partir disso, além de ferramentas específicas, como a Análise Macroergonômica de Estrutura (no inglês, MAS), a Macroergonomia utiliza e adapta outras ferramentas e metodologias para o seu escopo, como questionários, entrevistas semiestruturadas, pesquisa de campo e grupos de foco. Também é possível simular sistemas de trabalho em laboratório, onde o ergonomista manipula variáveis sociotécnicas, ou o sistema em si, em busca de respostas (HENDRICK, 2005, p.75-2). Apesar de serem aplicadas originalmente em ambientes industriais, as metodologias macroergonômicas apresentam conceitos e métodos que podem ser aplicados também em ambiente educacionais. Watson et al. (2009, p. 1042), por exemplo, defendem um uso mais amplo da Macroergonomia na educação. Para eles, a Ergonomia, nesse campo, ainda se concentra nas questões biomecânicas.

Os profissionais que produzem o material trabalham num ambiente pressionado pelas mudanças nas ferramentas de comunicação. Lidam com especificidades pedagógicas e precisam dialogar com colegas de formações diferentes das suas. Precisam de um sistema de gestão que entenda o seu trabalho de adaptação de conteúdo educacional para diferentes mídias. É uma tarefa técnica, mas também baseada na criatividade. São times que podem não funcionar nos modelos de produção mais comuns. Por ser sociotécnica e contextual, a abordagem macroergonômica pode ser exatamente o que a produção de material didático em EAD necessita. Afinal, trate-se de um sistema de trabalho multidisciplinar que ocorre num ambiente de pressões pedagógicas e tecnológicas.

O que as metodologias escolhidas, sejam do Design ou da Ergonomia, devem ter em comum é a participação dos atores envolvidos na busca por soluções. Dul e Ceylan (2010, p.14), analisando o trabalho de Shalley et al. (2004), dizem que todos os funcionários em uma organização podem produzir ideias novas e potencialmente úteis. $\mathrm{E}$ isso não só para produtos ou serviços, mas também para procedimentos de trabalho e solução de problemas do dia-a-dia. A inclusão dos usuários no processo é fundamental nas novas teorias de

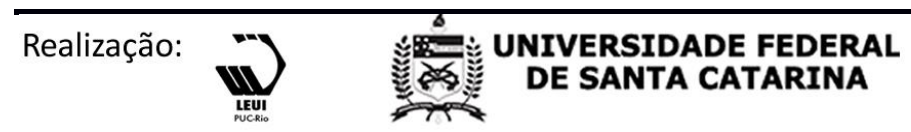


$16^{\circ}$ Ergodesign - Congresso Internacional de Ergonomia e Usabilidade de Interfaces Humano Tecnológica: Produto, Informações Ambientes Construídos e Transporte

$16^{\circ}$ USIHC - Congresso Internacional de Ergonomia e Usabilidade de Interfaces Humano Computador

CINAHPA | 2017 - Congresso Internacional de Ambientes Hipermídia para Aprendizagem.
Gestão baseadas no Design (BUCHANAN, 2015). Pode-se explicar essa importância fazendo uma relação com a visão do Design Participativo, que se caracteriza por projetar com o usuário ao invés de para o usuário (LIVARI apud SILVA, 2012). Nessa visão, os atores envolvidos são a melhor fonte de informações e respostas sobre a questão a ser abordada, já que vivenciam o objeto de estudo cotidianamente (SILVA, 2012).

No contexto multidisciplinar da EAD, é importante considerar não só as experiências cotidianas, mas também as necessidades pedagógicas na busca por soluções organizacionais. Por isso, é preciso usar ferramentas que façam os envolvidos contribuírem não só com o seu conhecimento teórico. A sua experiência prática cotidiana e seu conhecimento tácito também são fundamentais. Essa gama de informações centradas no usuário é o diferencial que o Design traz para o processo de gestão.

\section{Desdobramentos futuros}

Considerando o exposto até aqui, entende-se que o próximo passo de uma pesquisa seria aferir na prática a aplicabilidade da visão participativa do Design e/ou da Macroergonomia sobre a gestão da produção multidisciplinar de conteúdo em uma instituição de ensino superior. Para tanto, acreditase que a instituição a ser analisada deva possuir equipe própria de desenvolvimento de material didático, podendo reunir design instrucional, revisão, diagramação, criação do material de apoio na web (Moodle, por exemplo) e construção de diferentes mídias (animações, ilustrações, vídeos, etc.).

Propõe-se um estudo de caso, pois, segundo Bonoma (1985), é um método útil quando o fenômeno a ser estudado é amplo e complexo e nos casos em que o fenômeno não pode ser estudado fora do contexto onde naturalmente ocorre. Fachin (2003) afirma que o estudo de caso é empregado frequentemente em investigações que avaliam a eficácia de um conjunto de processos para auxiliar a sociedade.

Futuramente, os resultados finais do estudo podem ser aprofundados e comparados em outras pesquisas, para formatação de mais parâmetros sobre o uso do Design e da Macroergonomia como ferramentas de mudança e e gestão organizacional de pessoas e de processos em ambientes de EAD.

\section{BIBLIOGRAFIA}

ABED. Censo ead.br: relatório analítico da aprendizagem a distância no Brasil 2014. Curitiba: Ibpex, 2015.

\section{Censo ead.br: relatório analítico da} aprendizagem a distância no Brasil 2013. Curitiba, Ibpex, 2014.

ANDRADE, F. V.; LOPES, A. M. DE A. EaD: uma história de inovações tecnológicas no Brasil. Citi - 7. Congresso de Tecnologia da Informação. Anais...2012. Disponível em: $<\mathrm{http} / / / \mathrm{ww} w . e s s e n t i a e d i t o r a . i f f . e d u . b r / i n d e x . p h p / c i$ ti/article/view/2779>. Acesso em 09 set. 2016.

ARRUDA, E. P.; ARRUDA, D. E. P. Educação a Distância no Brasil: Políticas Públicas e democratização do acesso ao Ensino Superior. Belo Horizonte: Educação em Revista, v. 31, n. 3, p. 321-338, set. 2015. Disponível em:

$<$ http://www.scielo.br/scielo.php?script=sci_arttext \&amp;pid=S0102-

46982015000300321\&amp;lng=en\&amp;nrm=iso >. Acesso em 03 mai. 2016.

BEHAR, P. A. Modelos Pedagógicos em Educação a Distância. Porto Alegre: Artmed, 2008.

BONOMA, T. Case Research in Marketing: Opportunities, Problems, and Process. Chicago: Journal of Marketing Research, 1985.

\section{BRASIL. Balanço Social SESu 2003-2014.}

Brasília: Ministério da Educação, 2015. Disponível em: $<$ http://portal.mec.gov.br/sesu-secretaria-deeducacaosuperior/arquivos $>$. Acesso em 03 mai. 2016.

Censo da Educação Superior 2013 resumo técnico. Brasília: INEP (Instituto Nacional de Estudos e Pesquisas Educacionais
Realização:

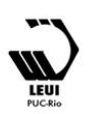




\section{$16^{\circ}$ \\ ERGODESIGN USIHC CINAHPA}

$16^{\circ}$ Ergodesign - Congresso Internacional de Ergonomia e Usabilidade de Interfaces Humano Tecnológica: Produto, Informações Ambientes Construídos e Transporte

$16^{\circ}$ USIHC - Congresso Internacional de Ergonomia e Usabilidade de Interfaces Humano Computador

CINAHPA | 2017 - Congresso Internacional de Ambientes Hipermídia para Aprendizagem.
AnísioTeixeira), 2015. Disponível em:

$<$ http://download.inep.gov.br/download/superior/ce nso/2013/resumo_tecnico_censo_educacao_superi or_2013.pdf>. Acesso em 02 mai.2016.

Lei $n^{\circ} 10.172$, que aprova o Plano

Nacional de Educação. Brasília: Diário Oficial da União, 2001. Disponível em:

<http://www.planalto.gov.br/ccivil_03/leis/L9394.h tm>. Acesso em 20 set. 2016.

. Lei $n^{\circ}$ 9.394, que estabelece as

Diretrizes e Bases da Educação Nacional.

Brasília: Diário Oficial da União, 1996. Disponível em:

<http://www.planalto.gov.br/ccivil_03/leis/L9394.h tm>. Acesso em 20 abr. 2016.

BROWN, T. Change by Design: How Design Thinking Transforms Organizations and Inspires Innovation, New York: Harper Business, 2009.

BUCHANAN, R. Worlds in the Making: Design, Management, and the Reform of Organizational Culture. Xangai: She Ji: The Journal of Design, Economics and Innovation, 2015. Disponível em: <http://www.sciencedirect.com/science/article/pii/ S2405872615000039>. Acesso em 30 mar. 2016.

BÚRIGO, C. C. D. et al. A Gestão Colaborativa no processo formativo da EAD. Revista Gestão Universitária na América Latina - GUAL, v. 9, n. 1, p. 165-176, 2016. Disponível em: $<$ https://periodicos.ufsc.br/index.php/gual/article/vi ew/1983-4535.2016v9n1p165/31558>. Acesso em 25 out. 2016.

COUTINHO, L. Aprendizagem on-line por meio de estruturas de cursos. In: LITTO, F. M.; FORMIGA, M. (Org.). Educação a distância: o estado da arte - Volume 1. São Paulo: Pearson, 2009. p. 310-316.

DUL, J.; CEYLAN, C. Work environments for employee creativity. Loughborough: Ergonomics, 2010. Disponível na internet por http em: < http://www.tandfonline.com/doi/abs/10.1080/0014 0139.2010.542833 >. Acesso em 01 mai. 2016.
FACHIN, O. Fundamentos de metodologia. São Paulo: Saraiva, 2003.

FORMIGA, M. A terminologia da EAD. In: LITTO, F. M.; FORMIGA, M. (Org.). Educação a distância: o estado da arte - Volume 1. São Paulo: Pearson, 2009. p. 39-46.

HENDRICK, H. W. Macroergonomic Methods. In: STANTON et al. (Org). Handbook of human factors and ergonomics methods. Boca Raton: CRC Press, 2005. p. 75-1-75-4.

HENDRICK, H. W.; KLEINER, B. M. Macro ergonomics: Theory, Methods, and Applications. New Jersey: CRC Press, 2002.

LITTO, F M. O atual cenário internacional da EAD. In: LITTO, F. M.; FORMIGA, M. (Org.). Educação a distância: o estado da arte - Volume 1. São Paulo: Pearson, 2009. p. 14-20.

MALLMANN, E. M.; CATAPAN, A. H. Materiais Didáticos em Educação a Distância: gestão e mediação pedagógica. Linhas, v. 8, n. 2, p. 63-75, 2007. Disponível em:

<http://www.periodicos.udesc.br/index.php/linhas/ article/view/1360>. Acesso em: 17 mai. 2016.

MATTAR, J. Interatividade e aprendizagem. In: LITTO, F. M.; FORMIGA, M. (Org.). Educação a distância: o estado da arte - Volume 1. São Paulo: Pearson, 2009. p. 112-120.

MOORE, M.; KEARSLEY, G. Educação a distância: uma visão integrada. São Paulo: Thompson Learning, 2007.

MORAN, J.; VALENTE, J.; ARANTES, V. (org.). Educação a Distância: Pontos e Contrapontos. São Paulo: Summus Editorial, 2011.

MORAN, J. A EAD no Brasil: cenário atual e caminhos viáveis de mudança, 2013. Disponível em: <http://www2.eca.usp.br/moran/wpcontent/uploads/2013/12/cenario.pdf $>$. Acesso em 02 out. 2016.

. Desafios da educação a distância no
Realização:

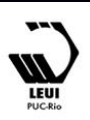




\section{$16^{\circ}$ \\ ERGODESIGN USIHC CINAHPA}

Brasil. Revista RCN, v. 12, p. 14-16, 2012. Disponível em:

<http://www2.eca.usp.br/moran/wpcontent/uploads/2013/12/desafios_ead.pdf >. Acesso em 02 out. 2016.

MOREIRA, M. A composição e o funcionamento da equipe de produção. In: LITTO, F. M.; FORMIGA, M. (Org.). Educação a distância: o estado da arte - Volume 1. São Paulo: Pearson, 2009. p. 370-378.

MUGNOL, M. Educação a Distância no Brasil: conceitos e fundamentos. Curitiba: Revista Diálogo Educacional, 2009. Disponível em: <http://google.redalyc.org/articulo.oa?id=1891172 98008>. Acesso em 20 abr. 2016.

NORDESTE, D. DO. Brasil é o 60 em uso de smartphones no mundo; na América Latina o País é o líder. Disponível em:

<http://diariodonordeste.verdesmares.com.br/suple mentos/tecno/online/brasil-e-o-6-em-uso-desmartphones-no-mundo-na-america-latina-o-paise-o-lider-1.1190571>. Acesso em: 4 out. 2016.

NUNES, I. B. A história da EAD no mundo. In: LITTO, F. M.; FORMIGA, M. (Org.). Educação a distância: o estado da arte - Volume 1. São Paulo: Pearson, 2009. p. 2-8.

O GLOBO. Usuários de internet móvel no Brasil crescem $7 \%$ nos últimos seis meses e chegam a 38,3 milhões. Disponível em:

<http://oglobo.globo.com/sociedade/tecnologia/usu arios-de-internet-movel-no-brasil-crescem-7-nosultimos-seis-meses-chegam-383-milhoes-

16195120>. Acesso em 4 out. 2016.

OLIVEIRA, D. S. DE. O uso do vídeo em EAD: desafios no processo de ensino aprendizagem.

Revista Cesuca Virtual: Conhecimento sem Fronteiras, v. 1, n.1, p. 1-15, 2013. Disponível em:

$<$ http://ojs.cesuca.edu.br/index.php/cesucavirtual/a rticle/view/422>. Acesso em 12 jul. 2016.

PALANGE, I. Os métodos de preparação de material para cursos on-line. In: LITTO, F. M.; FORMIGA, M. (Org.). Educação a distância: o $16^{\circ}$ Ergodesign - Congresso Internacional de Ergonomia e Usabilidade de Interfaces Humano Tecnológica: Produto, Informações Ambientes Construídos e Transporte

$16^{\circ}$ USIHC - Congresso Internacional de Ergonomia e Usabilidade de Interfaces Humano Computador

CINAHPA | 2017 - Congresso Internacional de Ambientes Hipermídia para Aprendizagem.

estado da arte - Volume 1. São Paulo: Pearson, 2009. p. 379-385.

SARAIVA, T. Educação a distância no Brasil: lições da história. Em Aberto, v.16, n. 70, abr./jun., p. 17-27, 1996. Disponível em: <http://www.rbep.inep.gov.br/index.php/emaberto/ article/viewFile/1048/950>. Acesso em 04 jun. 2016.

SILVA, N. A. N. Abordagens Participativas para o Design: Metodologias e plataformas sociotécnicas como suporte ao design interdisciplinar e aberto a participação. 2012. 67 f. Dissertação (Mestrado) -PUC-SP, Curso de Pós-Graduação em Tecnologias da Inteligência e Design Digital.

TEIXEIRA, O. A. F.; WESCHENFELDER, G. V. Evolução do EAD e as novas mídias. Revista Cesuca Virtual: Conhecimento sem Fronteiras, v. 1, n. 1, p. 1-21, 2013. Disponível em: <http://ojs.cesuca.edu.br/index.php/cesucavirtual/a rticle/view/425/210>. Acesso em 26 jun. 2016.

WATSON, J. et al. Macroergonomics in Education: On Your Mark, Set, GO!

Proceedings of the Human Factors and Ergonomics Society Annual Meeting. Anais...1 out. 2009.

Disponível na internet por http em: <http://hfs.sagepub.com/content/50/3/461>. Acesso em 20 jun. 2016. 